\title{
Modulation of host immune defenses by Aeromonas and Yersinia species: convergence on toxins secreted by various secretion systems
}

\author{
Jason A. Rosenzweig ${ }^{1,2 *}$ and Ashok K. Chopra ${ }^{3,4,5,6 *}$ \\ ${ }^{1}$ Department of Biology, Center for Bionanotechnology and Environmental Research, Texas Southern University, Houston, TX, USA \\ ${ }^{2}$ Department of Environmental and Interdisciplinary Sciences, Texas Southern University, Houston, TX, USA \\ ${ }^{3}$ Department of Microbiology and Immunology, University of Texas Medical Branch, Galveston, TX, USA \\ ${ }^{4}$ Sealy Center for Vaccine Development, University of Texas Medical Branch, Galveston, TX, USA \\ ${ }^{5}$ Institute of Human Infections and Immunity, University of Texas Medical Branch, Galveston, TX, USA \\ ${ }^{6}$ Galveston National Laboratory, University of Texas Medical Branch, Galveston, TX, USA
}

\section{Edited by:}

Yongqun He, University of Michigan

School of Medicine, USA

\section{Reviewed by:}

Richard D. Hayward, University

College London and Birkbeck,

University of London, UK

Glen C. Ulett, Griffith University,

Australia

\section{*Correspondence:}

Jason A. Rosenzweig, Department

of Biology, Center for

Bionanotechnology and

Environmental Research, Texas

Southern University, 3100 Cleburne

Street, Houston, TX 77004, USA

e-mail: rosenzweigja@tsu.edu;

Ashok K. Chopra, Department of

Microbiology and Immunology,

University of Texas Medical Branch,

301 University Boulevard,

Galveston, TX 77555-1070, USA

e-mail: achopra@utmb.edu
Like other pathogenic bacteria, Yersinia and Aeromonas species have been continuously co-evolving with their respective hosts. Although the former is a bonafide human pathogen, the latter has gained notararity as an emerging disease-causing agent. In response to immune cell challenges, bacterial pathogens have developed diverse mechanism(s) enabling their survival, and, at times, dominance over various host immune defense systems. The bacterial type three secretion system (T3SS) is evolutionarily derived from flagellar subunits and serves as a vehicle by which microbes can directly inject/translocate anti-host factors/effector proteins into targeted host immune cells. A large number of Gram-negative bacterial pathogens possess a T3SS empowering them to disrupt host cell signaling, actin cytoskeleton re-arrangements, and even to induce host-cell apoptotic and pyroptotic pathways. All pathogenic yersiniae and most Aeromonas species possess a T3SS, but they also possess T2- and T6-secreted toxins/effector proteins. This review will focus on the mechanisms by which the T3SS effectors Yersinia outer membrane protein $\mathrm{J}$ (YopJ) and an Aeromonas hydrophila AexU protein, isolated from the diarrheal isolate SSU, mollify host immune system defenses. Additionally, the mechanisms that are associated with host cell apoptosis/pyroptosis by Aeromonas T2SS secreted Act, a cytotoxic enterotoxin, and Hemolysin co-regulated protein ( $\mathrm{Hcp})$, an $A$. hydrophila T6SS effector, will also be discussed.

\section{Keywords: type 2-, -3, and -6 secretion systems, apoptosis, pyroptosis, actin cytoskeleton, effector proteins}

\section{INTRODUCTION}

Intricate host-pathogen interactions are constantly evolving as the latter has to combat formidable host immune defenses, resulting in expression/de-repression of genes and molecular mimicry. In some instances, strong immune responses to microbes select for escape mutants with the latter further honing the immune response to that variant pathogen, leading to an ongoing battle, as can be seen typically in human immunodeficiency virus escape mutants (Akahoshi et al., 2012; Yagita et al., 2013) and in Chlamydia trachomatis (Nunes et al., 2010). One classic example of this paradigm is programmed host cell death (caused by apoptosis, pyroptosis, and necrosis) which could benefit the host immune system (if clearing an intracellular pathogen) or could be co-opted by the pathogen as a means of eliminating undesirable host cells (e.g., innate immune cells) (Ulett and Adderson, 2006).

Whereas apoptosis is a "self-contained" event that does not stimulate a robust inflammatory response, both pyroptosis and necrosis of host cells release pro-inflammatory cytokines and their cytoplasmic contents into the extra-cellular milieu (Lamkanfi and Dixit, 2010). Apoptosis is a caspase-dependent process that drives embryonic development and is largely characterized by nuclear fragmentation and condensation, blebbing of the plasma membrane, and cell shrinkage. Since all of these physiological consequences occur intracellularly, no host cell cytoplasmic content is released into the extracellular environment, thereby preventing inflammation (Strasser et al., 2000).

Necrosis, by contrast, is a caspase-independent process that results in host cell swelling, disorganized and extensive chromatin hydrolysis, and cytoplasmic leakage (Berghe et al., 2010). Finally, caspase-1-dependent pyroptosis leads to secretion of pro-inflammatory cytokines interleukin-1 $\beta$ (IL-1 $\beta$ ) and IL-18. Caspase-1, interestingly, is not involved in apoptosis and is activated by one of four inflamasomes, which contain a member of the nucleotide-binding oligomerization domain-containing protein (Nod)-like receptor family, during pyroptosis (Lamkanfi and Dixit, 2009). Surprisingly, the pathogenic yersiniae can induce apoptosis, necrosis, and pyroptosis depending on the host-cell type infected (Monack et al., 1997; Ruckdeschel et al., 1997, 1998, 2001; Bergsbaken and Cookson, 2007; Zheng et al., 2012). Similarly, Aeromonas species are also able to induce apoptosis 
(through various caspase activation) (Galindo et al., 2004b, 2006a,b; Martins et al., 2007; Su et al., 2007; Sierra et al., 2007, 2010).

Gram-positive pathogens have also been shown to induce apoptosis in various cell types by disparate mechanisms. Nonsecreted lipotechoic acids (LTAs), well-conserved surface antigens on a wide variety of Gram-positive organisms, are such examples that induce apoptosis by distinct mechanisms in various cell types (Ulett and Adderson, 2006). Beyond LTAs that induce host cell apoptosis, Bacillus anthracis employs its lethal factor exotoxin (Park et al., 2002; Popov et al., 2002), Listeria monocytogenes utilizes listeriolysin, a cytolysin (Carrero et al., 2004), while the streptococci employ hemolysins (Ring et al., 2002; Liu et al., 2004). Ultimately, Gram-positive pathogens' apoptosis-inducing mechanisms are very diverse; they can typically be either intrinsic (e.g., mitochondrial dysfunction) or extrinsic whereby death domains are activated (Ulett and Adderson, 2006). Of the 27-members that belong to the Aeromonadaceae family, A. hydrophila, A. veronii, and $A$. caviae are frequently isolated as human pathogens, with most infections contracted via the fecal-oral route or through wounds (Altwegg et al., 1991; Kirov, 1993; Palu et al., 2006; Edberg et al., 2007). Aeromonas hydrophila is also a fish pathogen that can negatively impact the fishing industry. The majority of human Aeromonas infections result in self-limiting gastroenteritis or superficial skin infections. However, more threatening systemic infections include bacteremia, cellulitis, peritonitis, hemolyticuremic syndrome, and necrotizing fasciitis (Chopra et al., 1993, 1996; Janda et al., 1994; Merino et al., 1995; Kuhn et al., 1997; Chopra and Houston, 1999; Minnaganti et al., 2000; Brouqui and Raoult, 2001; Galindo et al., 2006a,b; Sha et al., 2013). Alarmingly, it seems as though instances of Aeromonas-induced necrotizing fasciitis are on the rise (Huang et al., 2011; Chang et al., 2012; Kao and Kao, 2012; Wu et al., 2012).

Of the 11 known Gram-negative Yersinia species, only Y. enterocolitica, Y. pseudotuberculosis, and Y. pestis are human pathogens. Strikingly, while Y. pseudotuberculosis and Y. enetrocolitica cause self-limiting gastroenteritis (Galindo et al., 2011), $Y$. pestis (transmitted by the bite of an infected flea) causes radically different diseases (bubonic, septicemic, or pneumonic plague) which have resulted in three major human pandemics as well as the great plagues of London in the mid-late $1600 \mathrm{~s}$ (Inglesby et al., 2000). Currently, the plague-causing bacterium can be treated with various antibiotics (Rosenzweig et al., 2011a), with levofloxacin recently being approved by the Food and Drug Administration against all forms of plague. However, there is no vaccine against this deadly pathogen (Rosenzweig et al., 2011b; Rosenzweig and Chopra, 2012).

As earlier mentioned, representatives of both the Yersinia and Aeromonas species are capable of causing gastroenteritis following the fecal-oral route of infection, and they similarly possess a type three secretion system (T3SS). The T3SS multiprotein complex/hyperstructure (Norris et al., 2012) is evolutionarily related to the bacterial flagella (Nguyen et al., 2000; Gophna et al., 2003) and enables rapid translocation of effector proteins directly into the targeted host cell cytoplasm, resulting in a number of anti-host consequences. Interestingly, whereas the yersiniae possess well-studied T3SS weaponry, Aeromonas species harbor well-defined T3- and T6-secretion systems (derived from phage injection machinery) along with its two identified effector protein substrates, Hemolysin co-regulated proteins (Hcps) and Valine glycine repeat G proteins (VgrGs) (Sierra et al., 2007, 2010; Vilches et al., 2009; Bergh et al., 2013; Sha et al., 2013). Interestingly, hemolysins in Streptococcus agalactiae, a Group B streptococci, have also been shown to induce apoptosis in phagocytic cells (Ulett and Adderson, 2006 and references therein). The yersiniae T6SSs have not been as extensively characterized; however, in Y. psuedotuberculosis, it is regulated by the transcriptional factor OmpR and appears to play a role in stress responses, quorum sensing, and maintenance of internal $\mathrm{pH}$ homeostasis (Zhang et al., 2011, 2013; Gueguen et al., 2013). In Y. pestis, the T6SS was found to secrete an Hcp-like autoagglutination factor (Podladchikova et al., 2011). Finally, Aeromonas species also employ the general secretory T2SS pathway to export cytotoxic enetrotoxin Act (with hemolytic, cytotoxic, and enterotoxic activities) into the extracellular milieu (Chopra and Houston, 1999). Within the yersiniae, the T3SS injects into the host 7 Yersinia outer membrane protein (Yop) effector proteins that have been identified as YopP/J, -H, -E, YopO/YpkA, YopT, YopK, and YopM; these Yops counteract host immune defenses by various mechanisms (Viboud and Bliska, 2005). Upon first encountering a Gram-negative pathogen, like Y. pestis, innate immune cells (e.g., macrophages and/or dendritic cells) recognize non-specific, pathogen-associated molecular patterns/microbe-associated molecular patterns (PAMPs/MAMPs), like lipopolysaccharide (LPS), lipoprotein, or flagellin. When PAMPs/MAMPs associate with their recognition receptors, e.g., Toll-like receptors (TLRs), various mitogen-activated protein (MAP) kinase (MAPK) and nuclear factor Kappa B (NF- $\mathrm{B})$ signaling pathways are activated resulting in the upregulation of IL-12, -18, and tumor necrosis factor alpha (TNF- $\alpha)$ proinflammatory cytokine production (Matsumoto and Young, 2009).

The yersiniae counteract the aforementioned inflammatory response when YopP/J acetylate I kappa B kinase (IKK) and MAPK kinases (MKKs), preventing their phosphorylation and subsequent activation. The disruption in these signaling events results in innate immune cells undergoing apoptosis (Orth, 2002; Mittal et al., 2006; Mukherjee et al., 2006). A more detailed description of Yersinia outer membrane protein J (YopJ) mechanisms of mollifying host defenses is discussed in a later section. YopE, $-\mathrm{H},-\mathrm{T}$, and YopO/YpkA all operate to disrupt actin cytoskeleton re-arrangements and phagocytosis, albeit by attacking unique and distinct targets. YopE is a GTPase-activating protein (GAP), while YopT targets Rac-1, RhoA and Cdc-42, and YopH, which is a tyrosine phosphotase, primarily targets focal adhesion complexes. YopO/YpkA, through its kinase activity, also targets Rac-1 and RhoA as well as actin directly. YopM localizes to the target cells' nuclei and disrupts cytokine IL-15 production by targeting ribosomal S6 protein kinase 1 (RSK1) and possibly protein kinase C-like 2 (PRK2) (Matsumoto and Young, 2009 and references therein). Finally, YopK was found to associate with the translocation pore and is believed to modulate inflammation (Brodsky et al., 2010).

As mentioned earlier, many Aeromonas species also possess a T3SS. In fact, within the fish pathogen A. salmonicida, four T3SSassociated effectors have been identified: AexT, AopP, AopH, and AopO (Braun et al., 2002; Dacanay et al., 2006; Fehr et al., 2006). 
Our laboratory recently identified an AexT-like protein (a novel T3SS effector, AexU) in a diarrheal isolate SSU of $A$. hydrophila (Sha et al., 2007). While Aeromonas outer protein P (AopP) disrupts NF- $\mathrm{B}$ signaling downstream of IKKB, unlike YopJ in the yersinaie, it does not disrupt the MAPK signaling pathway (Fehr et al., 2006). On the contrary, AexT and AexU both possess highly cytotoxic ADP-ribosyltranferase activity for host proteins (Braun et al., 2002; Sha et al., 2007). AopO and AopH remain poorly understood and are homologues of yersiniae YopO/YpkA and $\mathrm{YopH}$, respectively (Sha et al., 2007). Interestingly, we also demonstrated that an $A$. hydrophila $\triangle a \circ p B$ deletion mutant, unable to translocate effector Aops into host cells, exhibited greatly reduced virulence in a murine model of infection (Sha et al., 2005).

\section{T3SS EFFECTOR YopJ'S MECHANISMS OF ANTI-HOST ACTIVITY}

The yersiniae T3SS effector YopJ is an acetyltransferase as well as a de-ubiquitinase. Its anti-host activity involves blocking MAPK signaling and NF- $\kappa \mathrm{B}$ activation (Table 1). This aberrant signaling leads to significantly reduced production of both proinflammatory and anti-apoptotic host cytokines (Monack et al., 1997; Orth et al., 1999, 2000; Mukherjee et al., 2006). Shedding more light on the mechanism of YopJ anti-host activity, a report from Shrestha et al. (2012) identified that YopJ reduced the induction of eukaryotic initiation factor 2 (eIF2) in both yeast and mammalian cells, and that eIF2 signaling was required for YopJ-mediated inhibition of NF- $\kappa \mathrm{B}$ activation as well as pro-inflammatory cytokine production.

\section{TLR-2, NF-кB, and Nod2 signaling pathways all targeted by the versatile YopJ}

By using recombinant YopJ (rYopJ), it was determined that TLR-2 in murine macrophages was involved in YopJ-mediated apoptotic signaling by increasing production of caspases 3 and 8, IL-1 receptor associated kinase (IRAK)-4, Fas-associated protein with death domain (FADD), and phosphorylation of IкB and MAPK (Pandey and Sodhi, 2011). Together with this TLR2 apoptotic signaling, the ability of YopJ to target macrophage eIF2 signaling pathway required for inhibition of NF- $\mathrm{B}$ activation as well as pro-inflammatory cytokine production ultimately leads to host cell apoptosis (Shrestha et al., 2012). In a separate study employing a Drosophila model system, transforming growth factor (TGF)- $\beta$-activated kinase (TAK1), which is part of the immune NF- $\kappa \mathrm{B}$ signaling pathway independent of the TLR-2 signaling, was identified as the YopJ serine/threonine acetylation target (Paquette et al., 2012). Following YopJ acetylation of serine/threonine residues in the active site of Drosophila TAK1, its phosphorylation was blocked preventing activation of this kinase. Corroborating Drosophila studies, YopJ similarly modified and inhibited TAK1 in mammalian cells (Paquette et al., 2012).

Despite an earlier study demonstrating rYopJ activation of TLR-2 signaling in macrophages (Pandey and Sodhi, 2011), in vivo studies employing both Drosophila and macrophage models of infection clearly demonstrated that native YopJ indeed activated the NF- $\mathrm{B}$ signaling but not the TLR-2 signaling pathway (Paquette et al., 2012). It was proposed that following acetylation of key serine/threonine residues in the active sites of both RIP (receptor interacting protein 1)-like interacting caspaselike apoptosis regulatory protein kinase (RICK) and TAK1, YopJ prevented the interaction of RICK and Nod2, a NACHT-leucinerich repeats (NLRs) recognition receptors. Further, Nod2 interacted with caspase 1, promoting increased expression/production of IL1- $\beta$ and dissemination of $Y$. psudeotuberculosis through the gut epithelium (Meinzer et al., 2012). Perhaps this seeming contradiction of YopJ not signaling through TLR-2 during

Table 1 | The mechanisms of action of yersiniae effectors YopJ and YopK.

\begin{tabular}{|c|c|c|c|}
\hline Effector & Secretion system & Mechanisms of pathogenesis & References \\
\hline YopJ & T3SS & $\begin{array}{l}\text { Acetyltransferase and deubiquitinase that blocks MAPK and NF-кB signaling, causing } \\
\text { reduced production of pro-inflammatory and anti-apoptotic cytokines. }\end{array}$ & $\begin{array}{l}\text { Monack et al., 1997; Orth } \\
\text { et al., 1999, 2000; Mukherjee } \\
\text { et al., } 2006\end{array}$ \\
\hline
\end{tabular}

Reduced induction of eukaryotic initiation factor $4 . \quad$ Shrestha et al., 2012

Signals through TLR-2 to increase production of Caspase-3, -8, IRAK-4, FADD. Pandey and Sodhi, 2011

Serine threonine acetylation of TAK1 in Drosophila preventing its phosphorylation. Paquette et al., 2012

Blocks interaction of RICK and Nod2 acetylation of RICK and TAK 1; Nod2 then Meinzer et al., 2012

interacts with caspase-1 to increase expression of IL $1-\beta$ which promotes bacterial

dissemination through the gut.

\begin{tabular}{|c|c|c|c|}
\hline \multirow{2}{*}{ YopK } & \multirow[t]{2}{*}{ T3SS } & Regulates pyroptosis (via caspase-1). & Brodsky et al., 2010 \\
\hline & & $\begin{array}{l}\text { Regulates YopJ-mediated apopotosis in macrophages and facilitates bacterial } \\
\text { dissemination. }\end{array}$ & Peters et al., 2013 \\
\hline
\end{tabular}


in vivo studies while rYopJ was shown to signal through TLR-2 in vitro underscores one very important point. Different cell types and/or organisms likely possess disparate/specialized receptors used to recognize threatening pathogens. Viewed in this light, one can envision how within one cell type there could exist several unique receptors that could detect the same (or different products) derived from one pathogen. In the very delicate host-pathogen paradigm, every potential detection mechanism must be employed if the host is to successfully subvert the pathogenic threat. Collectively, YopJ has been observed disrupting TLR-2, Nod2, and the NF- $\kappa \mathrm{B}$ signaling pathways, making the T3SS-acetyltransferase a potent weapon for the pathogenic yersiniae.

\section{The yopK "switch" for YopJ activity}

Importantly, YopJ seems to function in concert with another Yop, YopK, which regulates YopJ activity (Table 1). Studies have shown that YopK appeared to regulate pyroptosis (via caspase 1) by Y. pseudotuberculosis (Brodsky et al., 2010) and YopJ-dependent apoptosis specifically in RAW 264.7 monocytic cells, thereby facilitating bacterial dissemination in a murine model of pneumonic plague (Peters et al., 2013). Despite YopK appearing dispensable for Y. pseudotuberculosis to induce caspase-1 mediated pyroptosis (Brodsky et al., 2010), it was required for optimum virulence of $Y$. pestis in a pneumonic murine model of infection (Peters et al., 2013). Further, cell culture $Y$. pestis infection models have also revealed that caspase 1 activation occurs downstream of cell necrosis, is independent of mitochondrial driven apoptosis, but does require cathepsin B activity (Zheng et al., 2012). Taken together, these data demonstrated that, at least in Y. pestis,
YopJ's ability to induce apoptosis is regulated by a YopK "switch" downstream of cell necrosis.

\section{T3SS EFFECTOR AexU's MECHANISMS OF ANTI-HOST ACTIVITY}

Shortly after a T3SS was identified in both A. salmonicida and A. hydrophila and implicated in their pathogenesis of both fish and animal/human hosts (Burr et al., 2002; Yu et al., 2004; Sha et al., 2005), we identified a novel T3SS-dependent AexT-like protein, referred to as AexU, in A. hydrophila (Sha et al., 2007; Sierra et al., 2007). AexT (Table 2), identified in the fish pathogen A. salmonicida, is homologous to the Pseudomonas aeruginosa ExoT/S and is also a bifunctional effector (Pederson et al., 1999; Sundin et al., 2004). Its amino terminus has YopE-like activity of yersiniae and can depolymerize actin by targeting RhoA, while its carboxy-terminus has highly cytotoxic ADP-ribosyltransferase (ADP-RT) activity for host proteins (Braun et al., 2002).

While the amino terminus of AexU from A. hydrophila SSU maintained $\sim 67 \%$ sequence similarity to its AexT counterpart, surprisingly, the AexU carboxy terminus had a unique sequence which did not share similarity with any other known protein in the NCBI database, despite full-length AexU maintaining ADPRT activity (Sha et al., 2007). Surprisingly, the purified full-length, truncated amino terminus, or truncated carboxy terminus of AexU all exhibited ADP-RT activity; however, the full-length AexU and its amino terminus exhibited higher ADP-RT activity than did the carboxy terminus of AexU alone (Sierra et al., 2007). Since the ADP-RT activity of the Pseudomonas homologue (ExoT/S) resides in its carboxy terminus, the aforementioned finding suggested a potentially unique evolution of $\mathrm{AexU}$ as an Aeromonas T3SS effector.

Table 2 | Aeromonad effector proteins AexT, AexU, Act, and Hcp mechanisms of action.

\begin{tabular}{|c|c|c|c|}
\hline Effector & Secretion system & Mechanism of pathogenesis & References \\
\hline AexT & T3SS & $\begin{array}{l}\text { Amino terminal activity targets RhoA and promotes actin depolymerization; carboxy terminal } \\
\text { ADP-ribosyltransferase activity. }\end{array}$ & Braun et al., 2002 \\
\hline \multirow[t]{3}{*}{ AexU } & T3SS & $\begin{array}{l}\text { Bifunctional-like AexT; activation of caspase- } 3 \text { and }-9 \text { and induction of cell rounding, chromatin } \\
\text { condensation; also required for virulence in mice. }\end{array}$ & Sierra et al., 2007 \\
\hline & & $\begin{array}{l}\text { GAP-activity (amino terminus) promotes apoptosis and disrupts the cell cytoskeleton as well } \\
\text { as NF-кB signaling; prevents signaling of c-Jun, JNK, I } \mathrm{B} \alpha \text {, and inhibits IL-6 and IL-8 secretion. }\end{array}$ & Sierra et al., 2010 \\
\hline & & $\begin{array}{l}\text { GAP-activity disruption of actin cytoskeleton mediated by down-regulating Rac- } 1 \text {; binding to } \\
\beta 4 \text {-integrin results in cytotoxicity. }\end{array}$ & Abolghait et al., 2011 \\
\hline \multirow[t]{2}{*}{ Act 2} & T2SS & Induced upregulation of apoptosis-related genes. & Galindo et al., 2003 \\
\hline & & $\begin{array}{l}\text { Activates MEK1, JNK, ERK1/2, and c-Jun of the MAPK pathway; induces membrane blebbing } \\
\text { and increased production of mitochondrial cytochrome C, caspase- } 3,-8 \text {, and }-9 \text {. }\end{array}$ & Galindo et al., 2004b \\
\hline \multirow[t]{3}{*}{ Hcp } & T6SS & Caspase 3 activation. & Suarez et al., 2008 \\
\hline & & Demonstrates anti-phagocytic properties. & Suarez et al., 2010 \\
\hline & & $\begin{array}{l}\text { Hcp-2 is part of the T6SS apparatus while Hcp- } 1 \text { negatively regulates motility and protease } \\
\text { production. }\end{array}$ & Sha et al., 2013 \\
\hline
\end{tabular}

RhoA, Rat sarcoma homolog gene family member A; GAP, GTPase activating protein; NF-kB, nuclear factor Kappa B; JNK, c-Jun N-terminal kinase; IL, interleukin; Rac-1, Rac GTPase activating protein 1; MEK1, MAP/ERK kinase 1; ERK1/2, extracellular signal-regulated kinase 1/2; MAPK, mitogen-activated protein kinases. 
Supporting this view, findings from a comprehensive genomic study evaluating an $A$. veronii group collection (derived from both clinical and environmental isolates) revealed that all 20 bacterial isolates possessed a functional T3SS as well as both AexU and AexT effectors. However, whereas AexU had a nucleotide substitution rate of $\sim 17 \%$ in its carboxy terminal region, AexT was much better conserved and demonstrated only a $\sim 4 \%$ substitution rate (Silver and Graf, 2009). Perhaps, the AexU carboxy terminus is evolving independently from its amino terminus allowing for not only the possibility of producing varying alleles but also producing a variety of AexU effectors capable of adapting to changing environments within the host (Figure 1)?

\section{Immunogenicity of AexU and its contribution to overall virulence}

In a cell culture infection model, our laboratory found that A. hydrophila AexU (Table 2) caused actin reorganization and cell rounding, chromatin condensation, and the activation of caspase 3 and 9, all hallmark features of apoptosis (Sierra et al., 2007). Furthermore, we reported that $A$. hydrophila AexU also possessed GAP activity which strongly promoted apoptosis and disrupted actin cytoskeletal rearrangements of the host cells (Sierra et al., 2010). Additionally, it was noted that A. hydrophila AexU prevented phosphorylation of c-Jun [a component of the activator protein 1 (AP-1) transcription factor], c-Jun N-terminal kinase (JNK) and IкB $\alpha$ (thereby disrupting their signaling cascades), and inhibited IL- 6 and -8 secretion from HeLa cells. Ultimately, AexU inhibited NF- $\kappa \mathrm{B}$ and inactivated Rho GTPases in the host cell (Sierra et al., 2010). For reasons unclear at this time, an AexU variant devoid of both GAP and ADP-RT activities, when produced from an aex $U$ null mutant of $A$. hydrophila, induced higher mouse mortality and increased pro-inflammatory cytokine production (Sierra et al., 2010). As was noted with YopJ, perhaps, to increase overall bacterial virulence through inflammation, evolutionary deactivation of AexU's activities provides a valuable "switch" for responding to various hosts?

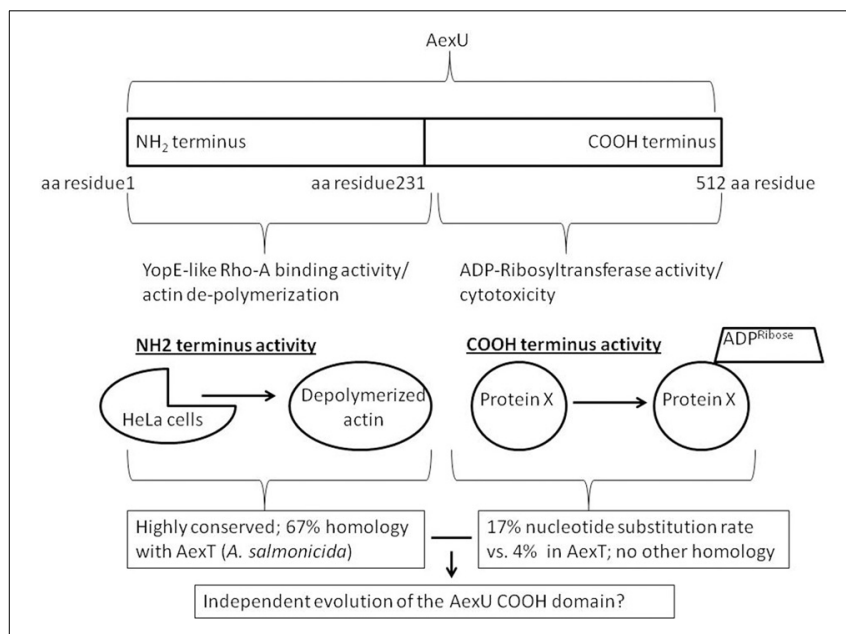

FIGURE 1 | The bifunctional AexU effector protein. The two independent activities of AexU are localized on either the $\mathrm{NH}$ - or the $\mathrm{COOH}$-termini. This allows for the possibility of an independently evolving $\mathrm{COOH}$-terminal activity.
In $P$. aeruginosa, it has been shown that the maturation of IL$1 \beta$ is negatively regulated by ExoS and is dependent on its ADPRT activity. In other words, ExoS devoid of this enzymatic activity when produced from the bacteria led to increased IL- $1 \beta$ production and pyroptosis of the host cells. However, AexU seemed to behave differently compared to ExoS as the former without the enzymatic activities was unable to alter IL-1 $\beta$ levels (Sierra et al., 2010). A. veronii AexU, in a GAP-dependent manner, was able to similarly disrupt actin cytoskeleton by down-regulating Rac1 in HeLa cells (Abolghait et al., 2011). Additionally, A. veronii AexU was found to co-localize with $\beta 4$-integrin resulting in cytotxicity for the host cells (Abolghait et al., 2011). Collectively, these data strongly demonstrated AexU's versatility as an effector protein by virtue of its ability to disrupt cell signaling, paralyze the host cell, activate caspases (initiating apoptosis), and interact with $\beta 4$-integren promoting host cell cytotoxicty. When evaluating AexU's contribution to mouse virulence and immunogenicity, we found that an A. hydrophila $\Delta a e x U$ deletion mutant caused significantly less mortality (40\% compared to $90-100 \%)$ in intraperitoneally-challenged mice than did infection with the isogenic parental strain (Sha et al., 2007). Importantly, rAexU provided protective immunity to mice when subsequently challenged with A. hydrophila (Sha et al., 2007). Additionally, the A. hydrophila $\Delta a \operatorname{ex} U$ deletion mutant was unable to disseminate within infected mice leaving their lungs, liver, and spleens relatively sterile (Sierra et al., 2010). The aforementioned findings raise the possibility of developing potential subunit and/or live-attenuated vaccine candidates for $A$. hydrophila, which is an emerging human pathogen.

\section{Aeromonas T2SS CYTOTOXIC ENTEROTOXIN (ACT) AND T6SS HCP EFFECTOR}

In addition to a functional T3SS, Aeromonas species also possess a T6SS (Suarez et al., 2008) as well as secrete a potent enterotoxin Act (Table 2) via the T2SS (Chopra and Houston, 1999). In efforts to better understand the host cell response to Act, our laboratory obtained transcriptome profiles of Act-exposed murine RAW 264.7 cells. Not surprisingly, of the 76 differentially expressed genes identified in Act-treated macrophages, many were involved in immune responses, including inflammation (Galindo et al., 2003). Additionally, several apoptosis-related genes were also found to be up-regulated including (but not limited to) Bcl-10 (promotes activation of NF- $\mathrm{B}$ and maturation of pro-caspase 9), BimEL (involved in p38 and JNK-associated apoptosis), and TNF receptor associated factor 1 (TRAF1, which regulates activation of NF- $\kappa \mathrm{B}$ and JNK). These transcriptome results with respect to apoptosis-related genes were confirmed by performing real-time PCR as well as functional assays for apoptosis (Galindo et al., 2003).

Since primary host cells may vary in their responses to a stimulant compared to the transformed cell lines, our laboratory evaluated transcriptome profiles of primary murine peritoneal macrophages after treatment with Act. We observed 66\% differential gene expression, mirroring our results seen with Act-exposed RAW 264.7 cells (Galindo et al., 2004a,b). However, differential expression of 28 genes unique to primary macrophages was also observed. The pro-apoptotic B-cell leukemia/lymphoma 
2 (Bcl-2) and Myeloid differentiation primary response 116 (MyD116) genes were upregulated, while interferon consensus binding proteins 8 (IRF-8-involved in immune responses) was downregulated in Act-treated primary cells (Galindo et al., 2004a). When the effect of Act on human HT-29 colonic epithelial cells' transcriptome profiles was evaluated, we noted upregulation of genes involved in immune responses (e.g., IL-8) and apoptosis (e.g., Bcl-2-like genes) as well as phosphorylation of MAPKs (e.g., p38 kinase, extracellular signal-regulated kinase 1/2 [ERK1/2], and JNK) (Galindo et al., 2005), mirroring what was observed earlier in our mouse macrophage studies (Galindo et al., 2003, 2004a,b). Further, through proteomic analysis, we determined that Act increased phosphorylation/activation of cyclic AMPresponse element binding protein (CREB), c-Jun, protein kinase $\mathrm{C}$, and signal transducer and activator of transcription 3 (STAT3) (Galindo et al., 2005).

Realizing that Act induces apoptosis in both cultured and primary macrophages, we elucidated the molecular mechanisms and specifically interrogated the MAPK signaling pathway. We found that, in various cell types, Act exposure resulted in activation of JNK and ERK1/2. Furthermore, Act induced activation/phosphorylation of MAPK upstream factors MKK3/6, MKK4 and MAP/ERK kinase 1 (MEK1) as well as downstream transcription factor c-Jun (Galindo et al., 2004b). With regards to apoptosis, Act induced classical membrane blebbing, increased production of mitochondrial cytochrome $c$ and apoptosis-inducing factor, in addition to caspase-3, -8, and -9 activation (Galindo et al., 2004b). When we screened for interactions between Act and both human and yeast proteins (using proArrays), Act was found to bind 9 human proteins (out of $\sim 1800$ proteins screened). Of the 9, synaptosomal-associated protein 23 (SNAP23), galectin-3, and guanylate kinase 1 (GUK-1) were knocked down in murine macrophages and HT-29 epithelial cells (using small inhibitory RNA), with the former two resulting in reduced induction of apoptosis following Act exposure (Galindo et al., 2006a,b). Interestingly, we also observed that DNA adenine methyltransferase (Dam) and Glucose inhibited division protein (GidA) both work to positively influence act gene expression and its associated hemolytic activity (Erova et al., 2012). Interestingly, the Gram-positive pathogen, Staphylococcus aureus, also secretes a potent, pro-apoptotic enterotoxin, the superantigen enterotoxin B. The aforementioned enterotoxin specifically targets T-cells and activates FAS receptor signaling (Ulett and Adderson, 2006 and references therein).

The Aeromonas T6SS has two identified effector protein substrates, Hcps and VgrGs (Sha et al., 2013). A. hydrophila's Hcp (Table 2) is a powerful effector substrate and once translocated into the targeted host cell cytoplasm, apoptosis ensues following caspase 3 activation (Suarez et al., 2008). We also demonstrated that Hcp paralyzes macrophages thereby preventing phagocytosis (Suarez et al., 2010). Curiously, multiple copies of Hcp are present in T6SS-possessing bacteria suggesting either redundancy of function and/or dosage-related functional influences (Mougous et al., 2006). The Aeromonas gene duplications and various alleles are likely a byproduct of co-evolution occurring in both bacterial pathogens and their respective hosts.
In A. hydrophila SSU, the $2 \mathrm{Hcp}$ paralogs cluster to two regions of the chromosome and influence virulence-associated properties differently, demonstrating little functional redundancy (Seshadri et al., 2006; Suarez et al., 2008; Sha et al., 2013). Hcp-2, located inside the T6SS cluster appeared to function structurally in forming the T6SS apparatus while Hcp-1, located at a distal chromosomal site functioned more as an effector (Sha et al., 2013). More specifically, only Hcp-1 worked to negatively regulate bacterial motility and protease production (both required for optimal virulence) whereas both paralogs were required for optimal virulence and dissemination to peripheral organs in a murine model of infection (Sha et al., 2013). When considering the impressive arsenal available to A. hydrophila that includes a T3SS, a T6SS as well as a potent T2SS secreted Act, it becomes less surprising that human infections caused by this emerging pathogen are on the rise.

\section{CONCLUSION}

In context of an intricate host-bacterial pathogen co-evolutionary paradigm, at times it become difficult to determine whether the resulting outcomes better benefit the host or the pathogen. For example, following inhibition of NF- $\kappa$ B and MAPK signaling pathways, Yersinia species through their generic PAMP/danger signals (e.g., LPS or flagellin), can induce pyroptosis a specialized inflammation-associated apoptosis that involves the activation of caspase 1 (Philip and Brodsky, 2012 and references therein). Inflammation is, in reality, a double-edged sword. If of short duration and localized, it can serve to reduce extent of bacterial infection preventing systemic spread of the pathogen. However, if persistent and/or systemic, inflammation can damage host tissue and potentially promote bacterial spread contributing to bacterial pathogenesis. These two scenarios underscore the intricacies of the host-pathogen interaction as well as reveal how co-evolution can be shaped. The yersiniae T3SS effector, YopJ, is a perfect example of such an ambiguity. Despite its potent immunomodulatory capabilities, YopJ was largely dispensable for virulence in a rat model of bubonic plague (Lemaitre et al., 2006). Further, there has been evolutionary selective pressure against excessive YopJ secretion in order to achieve maximal virulence during plague infections (Zauberman et al., 2006; Brodsky and Medzhitov, 2008). What does this all mean? Does YopJ's powerful ability to induce inflammation benefit the pathogen or the host? Perhaps viewed in this light, the cost to benefit ratio nears "1" making YopJ a "circumstantial virulence factor" depending on the Yersinia pathogen in question, the route of infection, the immunodisposition of the host, etc.

The T3SS is a powerful vehicle of effector protein delivery shared by many Gram-negative pathogens. The pathogenic Aeromonas species also possess a functional T3SS that delivers 4 effector proteins into targeted host cells. The YopJ homolog, AopP disrupts NF- $\kappa \mathrm{B}$ signaling downstream of IKKB but, unlike YopJ in the yersinaie, does not disrupt the MAPK signaling pathway (Fehr et al., 2006). AexU, is an extremely versatile Aeromonas T3SS bifunctional effector that possesses both GAP activity (like the yersiniae YopE) as well as ADP-RT activity. Like YopJ, AexU induces apoptosis and targets NF- $\kappa \mathrm{B}$ signaling. However, unlike in the yersinaie which lack clearly defined T6SS-virulence factors, 
Aeromonas species possess well-defined T6SS-associated virulence factors and even a T2SS-secreted toxin (Act) creating a much wider arsenal. The T6SS Hcp paralogs sharing limited functional redundancy suggest that co-evolution might have shaped the gene duplication event as well as provide the necessary selection pressure that maintains the multiple copies in the chromosome. Taken together, T3SSs effectors in both the yersiniae and Aeromonas species as well as T2- and T6SS effectors in Aeromonas species converge on modulating the host immune response to promote bacterial virulence.

\section{ACKNOWLEDGMENTS}

We would like to greatly acknowledge lively discussions and insights provided by Drs. Jian Sha (UTMB, Galveston), Kurt Schesser (University of Miami), and Greg Plano (University of Miami). Work on this review was supported by National Aeronautics and Space Administration (NASA) cooperative agreement NNX08B4A47A (Jason A. Rosenzweig), and NIH/NIAID AI064389 grant awarded to Ashok K. Chopra.

\section{REFERENCES}

Abolghait, S. K., Iida, T., Kodama, T., Cantarelli, V. V., Akeda, Y., and Honda, T. (2011). Recombinant AexU effector protein of Aeromonas veronii bv. sobria disrupts the actin cytoskeleton by downregulation of Racl and induces direct cytotoxicity to $\beta 4$-integrin expressing cell lines. Microb. Pathog. 51, 454-465. doi: 10.1016/j.micpath.2011.09.006

Altwegg, M., Martinetti Lucchini, G., Luthy-Hottenstein, J., and Rohrbach, M. (1991). Aeromonas-associated gastroenteritis after consumption of contaminated shrimp. Eur. J. Clin. Microbiol. Infect. Dis. 10, 44-45. doi: 10.1007/BF01967100

Akahoshi, T., Chikata, T., Tamura, Y., Gatanaga, H., Oka, S., and Takiguchi, M. (2012) Selection and accumulation of an HIV-1 escape mutant by three types of HIV-1-specific cytotoxic T lymphocytes recognizing wild-type and/or escape mutant epitopes. J. Virol. 86, 1971-1981. doi: 10.1128/JVI.06470-11

Bergh, P. V., Burr, S. E., Benedicenti, O., von Siebenthal, B., Frey, J., and Wahli, T. (2013). Antigens of the type-three secretion system of Aeromonas salmonicida subsp. salmonicida prevent protective immunity in rainbow trout. Vaccine. doi: 10.1016/j.vaccine.2013.08.057. [Epub ahead of print].

Berghe, T. V., Vanlangenakker, N., Parthoens, E., Deckers, W., Devos, M., Festjens, N., et al. (2010). Necroptosis, necrosis and secondary necrosis converge on similar cellular disintegration features. Cell Death Differ. 17, 922-930. doi: $10.1038 /$ cdd.2009.184

Bergsbaken, T., and Cookson, B. T. (2007). Macrophage activation redirects Yersinia-infected host cell death from apoptosis to caspase-1-dependent pyroptosis. PLoS Pathog. 3:e161. doi: 10.1371/journal.ppat.0030161

Braun, M., Stuber, K., Schlatter, Y., Wahli, T., Kuhnert, P., and Frey, J. (2002). Characterization of an ADP-ribosyltransferase toxin (AexT) from Aeromonas salmonicida subsp. salmonicida. J. Bacteriol. 184, 1851-1858. doi: 10.1128/JB.184.7.1851-1858.2002

Brodsky, I., and Medzhitov, R. (2008). Reduced secretion of YopJ by Yersinia limits in vivo cell death but enhances bacterial virulence. PLoS Pathog. 4:e1000067. doi: 10.1371/journal.ppat. 1000067

Brodsky, I., Palm, N., Sadanand, S., Ryndak, M., Sutterwala, F., Flavell, R.A., et al. (2010). A Yersinia effector protein promotes virulence by preventing inflammasome recognition of the type III secretion system. Cell Host Microbe 7, 376-387. doi: 10.1016/j.chom.2010.04.009

Brouqui, P., and Raoult, D. (2001). Endocarditis due to rare and fastidious bacteria. Clin. Microbiol. Rev. 14, 177-207. doi: 10.1128/CMR.14.1.177-207.2001

Burr, S. E., Stuber, K., Wahli, T., and Frey, J. (2002). Evidence for a type III secretion system in Aeromonas salmonicida subsp. salmonicida. J. Bacteriol. 184, 5966-5970. doi: 10.1128/JB.184.21.5966-5970.2002

Carrero, J. A., Calderon, B., and Unanue, E. R. (2004). Listeriolysin O from Listeria monocytogenes is a lymphocyte apoptogenic molecule. J. Immunol. 172, 4866-4874.
Chang, H., Hung, Y. S., Shie, S. S., and Lin, T. L. (2012) Fulminant necrotizing fasciitis caused by Aeromonas sobria in neutropenic patients. Intern. Med. 51, 3287-3290. doi: 10.2169/internalmedicine.51.6281

Chopra, A. K., and Houston, C. W. (1999). Enterotoxins in Aeromonasassociated gastroenteritis. Microbes Infect. 1, 1129-1137. doi: 10.1016/S12864579(99)00202-6

Chopra, A. K., Houston, C. W., Peterson, J. W., and Jin, G. F. (1993). Cloning, expression, and sequence analysis of a cytolytic enterotoxin gene from Aeromonas hydrophila. Can. J. Microbiol. 39, 513-523. doi: 10.1139/ m93-073

Chopra, A. K., Peterson, J. W., Xu, X. J., Coppenhaver, D. H., and Houston, C. W. (1996). Molecular and biochemical characterization of a heat-labile cytotonic enterotoxin from Aeromonas hydrophila. Microb. Pathog. 21, 357-377. doi: 10.1006/mpat.1996.0068

Dacanay, A., Knickle, L., Solanky, K. S., Boyd, J. M., Walter, J. A., Brown, L. L., et al. (2006). Contribution of the type III secretion system (TTSS) to virulence of Aeromonas salmonicida subsp. salmonicida. Microbiology 152, 1847-1856. doi: 10.1099/mic.0.28768-0

Edberg, S. C., Browne, F. A., and Allen, M. J. (2007). Issues for microbial regulation: Aeromonas as a model. Crit. Rev. Microbiol. 33, 89-100. doi: $10.1080 / 10408410601172180$

Erova, T. E., Kosykh, V. G., Sha, J., and Chopra, A. K. (2012). DNA adenine methyltransferase (Dam) controls the expression of the cytotoxic enterotoxin (act) gene of Aeromonas hydrophila via tRNA modifying enzyme-glucoseinhibited division protein (GidA). Gene 498, 280-287. doi: 10.1016/j.gene.2012. 02.024

Fehr, D., Casanova, C., Liverman, A., Blazkova, H., Orth, K., Dobbelaere, D., et al. (2006). AopP, a type III effector protein of Aeromonas salmonicida, inhibits the NF-kappaB signalling pathway. Microbiology 152, 2809-2818. doi: 10.1099/mic.0.28889-0

Galindo, C. L., Fadl, A. A., Sha, J., and Chopra, A. K. (2004a). Microarray analysis of Aeromonas hydrophila cytotoxic enterotoxin-treated murine primary macrophages. Infect. Immun. 72, 5439-5445. doi: 10.1128/IAI.72.9.54395445.2004

Galindo, C. L., Fadl, A. A., Sha, J., Gutierrez, C. Jr., Popov, V. L., Boldogh, I., et al. (2004b). Aeromonas hydrophila cytotoxic enterotoxin activates mitogen activated protein kinases and inducesapoptosis in murine macrophages and human intestinal epithelial cells. J. Biol. Chem. 279, 37597-37612. doi: 10.1074/jbc.M404641200

Galindo, C. L., Fadl, A. A., Sha, J., Pillai, L., Gutierrez, C. Jr., and Chopra, A. K. (2005). Microarray and proteomics analyses of human intestinal epithelial cells treated with the Aeromonas hydrophila cytotoxic enterotoxin. Infect. Immun. 73, 2628-2643. doi: 10.1128/IAI.73.5.2628-2643.2005

Galindo, C. L., Gutierrez, C. Jr., and Chopra, A. K. (2006a). Potential involvement of galectin-3 and SNAP23 in Aeromonas hydrophila cytotoxic enterotoxin-induced host cell apoptosis. Microb. Pathog. 40, 56-68. doi: 10.1016/j.micpath.2005.11.001

Galindo, C. L., Sha, J., Fadl, A. A., Pillai, L., and Chopra, A. K. (2006b). Host immune response to Aeromonas virulence factors. Curr. Immunol. Rev. 2, 13-26. doi: 10.2174/157339506775471910

Galindo, C. L., Rosenzweig, J. A., Kirtley, M. L., and Chopra, A. K. (2011). Pathogenesis of Y. enterocolitica and Y. pseudotuberculosis in human yersiniosis. J. Pathog. 2011, 182051. doi: 10.4061/2011/182051

Galindo, C. L., Sha, J., Ribardo, D. A., Fadl, A. A., Pillai, L., and Chopra, A. K. (2003). Identification of Aeromonas hydrophila cytotoxic enterotoxin-induced genes in macrophages using microarrays. J. Biol. Chem. 278, 40198-40212. doi: 10.1074/jbc.M305788200

Gophna, U., Ron, E. Z., and Graur, D. (2003). Bacterial type III secretion systems are ancient and evolved by multiple horizontal-transfer events. Gene 312, 151-163. doi: 10.1016/S0378-1119(03)00612-7

Gueguen, E., Durand, E., Zhang, X. Y., d'Amalric, Q., Journet, L., and Cascales, E. (2013) Expression of a Yersinia pseudotuberculosis type VI secretion system is responsive to envelope stresses through the OmpR transcriptional activator. PLOS ONE. 8:e66615. doi: 10.1371/journal. pone. 0066615

Huang, K. F., Hung, M. H., Lin, Y. S., Lu, C. L., Liu, C., Chen, C. C., et al. (2011). Independent predictors of mortality for necrotizing fasciitis: a retrospective analysis in a single institution. J. Trauma 71, 467-473. doi: 10.1097/TA.0b013e318220d7fa 
Inglesby, T. V., Dennis, D. T., Henderson, D. A., Bartlett, J. G., Ascher, M. S., Eitzen, E., et al. (2000). Plague as a biological weapon: medical and public health management. Working group on civilian biodefense. JAMA 283, 2281-2290. doi: 10.1001/jama.283.17.2281

Janda, J. M., Guthertz, L. S., Kokka, R. P., and Shimada, T. (1994). Aeromonas species in septicemia: laboratory characteristics and clinical observations. Clin. Infect. Dis. 19, 77-83. doi: 10.1093/clinids/19.1.77

Kao, T. L., and Kao, M. L. (2012). A fatal case of necrotizing Aeromonas schubertii fasciitis after penetrating injury. Am. J. Emerg. Med. 30, 258.e3-258.e5. doi: 10.1016/j.ajem.2010.10.028

Kirov, S. M. (1993). The public health significance of Aeromonas spp. in foods. Int J. Food Microbiol. 20, 179-198. doi: 10.1016/0168-1605(93)90164-C

Kuhn, I., Albert, M. J., Ansaruzzaman, M., Bhuiyan, N.A., Alabi, S.A., Islam, M.S., et al. (1997). Characterization of Aeromonas spp. isolated from humans with diarrhea, from healthy controls, and from surface water in Bangladesh. J. Clin. Microbiol. 35, 369-373.

Lamkanfi, M., and Dixit, V. M. (2009). Inflammasomes: guardians of cytosolic sanctity. Immunol. Rev. 227, 95-105. doi: 10.1111/j.1600-065X.2008. 00730.x

Lamkanfi, M., and Dixit, V. M. (2010). Manipulation of host cell death pathways during microbial infections. Cell Host Microbe 8, 44-54. doi: 10.1016/j.chom.2010.06.007

Lemaitre, N., Sebbane, F., Long, D., and Hinnebusch, B. (2006). Yersinia pestis YopJ suppresses tumor necrosis factor alpha induction and contributes to apoptosis of immune cells in the lymph node but is not required for virulence in a rat model of bubonic plague. Infect. Immun. 74, 5126-5131. doi: 10.1128/IAI.00219-06

Liu, G. Y., Doran, K. S., Lawrence, T., Turkson, N., Puliti, M., Tissi, L., et al. (2004). Sword and shield: Linked group B streptococcal \{beta\}-hemolysin/cytolysin and carotenoid pigment function to subvert host phagocyte defense. Proc. Natl. Acad. Sci. U.S.A. 101, 14491-14496. doi: 10.1073/pnas.0406143101

Matsumoto, H., and Young GM. (2009). Translocated effectors of Yersinia. Curr. Opin. Microbiol. 12, 94-100. doi: 10.1016/j.mib.2008.12.005

Martins, L. M., Catani, C. F., Falcón, R. M., Carbonell, G. V., Azzoni, A. A., and Yano, T. (2007) Induction of apoptosis in Vero cells by Aeromonas veronii biovar sobria vacuolating cytotoxic factor. FEMS Immunol. Med. Microbiol. 49, 197-204. doi: 10.1111/j.1574-695X.2006.00176.x

Meinzer, U., Barreau, F., Esmiol-Welterlin, S., Jung, C., Villard, C., Léger, T., et al. (2012). Yersinia pseudotuberculosis effector YopJ subverts the Nod2/RICK/TAK1 pathway and activates caspase-1 to induce intestinal barrier dysfunction. Cell Host Microbe. 11, 337-351. doi: 10.1016/j.chom.2012.02.009

Merino, S., Rubires, X., Knochel, S., and Tomas, J. M. (1995). Emerging pathogens: Aeromonas spp. Int. J. Food Microbiol. 28, 157-168. doi: 10.1016/01681605(95)00054-2

Minnaganti, V. R., Patel, P. J., Iancu, D., Schoch, P. E., and Cunha, B. A. (2000). Necrotizing fasciitis caused by Aeromonas hydrophila. Heart Lung 29, 306-308. doi: $10.1067 / \mathrm{mhl} .2000 .106723$

Mittal, R., Peak-Chew, S. Y., and McMahon, H. T. (2006). Acetylation of MEK2 and I kappa B kinase (IKK) activation loop residues by YopJ inhibits signaling. Proc. Natl. Acad. Sci. U.S.A. 103, 18574-18579. doi: 10.1073/pnas.0608995103

Mougous, J. D., Cuff, M. E., Raunser, S., Shen, A., Zhou, M., Gifford, C. A., et al. (2006). A virulence locus of Pseudomonas aeruginosa encodes a protein secretion apparatus. Science 312, 1526-1530. doi: 10.1126/science.1128393

Monack, D., Mecsas, J., Ghori, N., and Falkow, S. (1997). Yersinia signals macrophages to undergo apoptosis and YopJ is necessary for this cell death. Proc. Natl. Acad. Sci. U.S.A. 94, 10385-10390. doi: 10.1073/pnas.94.19.10385

Mukherjee, S., Keitany, G., Li, Y., Wang, Y., Ball, H. L., Goldsmith, E. J., et al. (2006). Yersinia YopJ acetylates and inhibits kinase activation by blocking phosphorylation. Science 312, 1211-1214. doi: 10.1126/science.1126867

Nguyen, L., Paulsen, I. T., Tchieu, J., Hueck, C. J., and Saier, M. H. (2000). Phylogenetic analyses of the constituents of Type III protein secretion systems. J. Mol. Microbiol. Biotechnol. 2, 125-144.

Norris, V., Menu-Bouaouiche, L., Becu, J. M., Legendre, R., Norman, R., and Rosenzweig, J. A. (2012). Hyperstructure interactions influence the virulence of the type 3 secretion system in yersiniae and other bacteria. Appl. Microbiol. Biotechnol. 96, 23-36. doi: 10.1007/s00253-012-4325-4

Nunes, A., Nogueira, P. J., Borrego, M. J., and Gomes, J. P. (2010). Adaptive evolution of the Chlamydia trachomatis dominant antigen reveals distinct evolutionary scenarios for B- and T-cell epitopes: worldwide survey. PLoS ONE 5:e13171. doi: 10.1371/journal.pone.0013171

Orth, K. (2002). Function of Yersinia effector YopJ. Curr. Opin. Microbiol. 5, 38-43. doi: 10.1016/S1369-5274(02)00283-7

Orth, K., Palmer, L., Bao, Z., Stewart, S., Rudolph, A., Bliska, J.B., et al. (1999). Inhibition of the mitogen-activated protein kinase kinase superfamily by a Yersinia effector. Science 285, 1920-1923. doi: 10.1126/science.285.5435.1920

Orth, K., Xu, Z., Mudgett, M., Bao, Z., Palmer, L., Bliska, J. B., et al. (2000). Disruption of signaling by Yersinia effector YopJ, a ubiquitin-like protein protease. Science 290, 1594-1597. doi: 10.1126/science.290.5496.1594

Palu, A. P., Gomes, L. M., Miguel, M. A., Balassiano, I. T., Queiroz, M. L., FreitasAlmeida, A. C., et al. (2006). Antimicrobial resistance in food and clinical Aeromonas isolates. Food Microbiol. 23, 504-509. doi: 10.1016/j.fm.2005.07.002

Pandey, A. K., and Sodhi, A. (2011). Recombinant YopJ induces apoptotic cell death in macrophages through TLR2. Mol. Immunol. 48, 392-398. doi: 10.1016/j.molimm.2010.07.018

Park, J. M., Greten, F. R., Li, Z. W., and Karin, M. (2002). Macrophage apoptosis by anthrax lethal factor through p38 MAP kinase inhibition. Science 297, 2048-2051. doi: 10.1126/science.1073163

Paquette, N., Conlon, J., Sweet, C., Rus, F., Wilson, L., Pereira, A., et al. (2012). Serine/threonine acetylation of TGF $\beta$-activated kinase (TAK1) by Yersinia pestis YopJ inhibits innate immune signaling. Proc. Natl. Acad. Sci. U.S.A. 109 12710-12715. doi: 10.1073/pnas.1008203109

Pederson, K. J., Vallis, A. J., Aktories, K., Frank, D. W., and Barbieri, J. T. (1999). The amino-terminal domain of Pseudomonas aeruginosa ExoS disrupts actin filaments via small-molecular-weight GTP-binding proteins. Mol. Microbiol. 32, 393-401. doi: 10.1046/j.1365-2958.1999.01359.x

Peters, K. N., Dhariwala, M. O., Hughes Hanks, J. M., Brown, C. R., and Anderson, D. M. (2013). Early apoptosis of macrophages modulated by injection of Yersinia pestis YopK promotes progression of primary pneumonic plague. PLoS Pathog. 9:e1003324. doi: 10.1371/journal.ppat.1003324

Philip, N. H., and Brodsky, I. E. (2012). Cell death programs in Yersinia immunity and pathogenesis. Front. Cell. Infect. Microbiol. 2:149. doi: 10.3389/fcimb.2012.00149

Podladchikova, O., Antonenka, U., Heesemann, J., and Rakin, A. (2011) Yersinia pestis autoagglutination factor is a component of the type six secretion system. Int. J. Med. Microbiol. 301, 562-569. doi: 10.1016/j.ijmm.2011.03.004

Popov, S. G., Villasmil, R., Bernardi, J., Grene, E., Cardwell, J., Popova, T., et al. (2002). Lethal toxin of Bacillus anthracis causes apoptosis of macrophages. Biochem. Biophys. Res. Commun. 293, 349-355. doi: 10.1016/S0006-291X(02)00227-9

Ring, A., Braun, J. S., Pohl, J., Nizet, V., Stremmel, W., and Shenep, J. L. (2002). Group B streptococcal beta-hemolysin induces mortality and liver injury in experimental sepsis. J. Infect. Dis. 185, 1745-1753. doi: 10.1086/340818

Rosenzweig, J. A., Brackman, S. M., Kirtley, M. L., Sha, J., Erova, T. E., Yeager, L. A. et al. (2011a). Cethromycin-mediated protection against the plague pathogen Yersinia pestis in a rat model of infection and comparison with levofloxacin. Antimicrob. Agents Chemother. 55, 5034-5042. doi: 10.1128/AAC.00632-11

Rosenzweig, J. A., and Chopra, A. K. (2012). The future of plague vaccines: hopes raised by a surrogate, live-attenuated recombinant vaccine candidate. Expert Rev. Vaccines. 11, 659-661. doi: 10.1586/erv.12.34

Rosenzweig, J. A., Jejelowo, O., Sha, J., Erova, T. E., Brackman, S. M., Kirtley, M. L., et al. (2011b). Progress on plague vaccine development. Appl. Microbiol. Biotechnol. 91, 265-286. doi: 10.1007/s00253-011-3380-6

Ruckdeschel, K., Harb, S., Roggenkamp, A., Hornef, M., Zumbihl, R., Kohler, S., et al. (1998). Yersinia enterocolitica impairs activation of transcription factor NF-kappaB:involvement in the induction of programmed cell death and in the suppression of the macrophage tumor necrosis factor alpha production. J. Exp. Med. 187, 1069-1079. doi: 10.1084/jem.187.7.1069

Ruckdeschel, K., Mannel, O., Richter, K., Jacobi, C. A., Trulzsch, K., Rouot, B. et al. (2001). Yersinia outer protein P of Yersinia enterocolitica simultaneously blocks the nuclear factor-kappa B pathway and exploits lipopolysaccharide signaling to trigger apoptosis in macrophages. J. Immunol. 166, 1823-1831.

Ruckdeschel, K., Roggenkamp, A., Lafont, V., Mangeat, P., Heesemann, J., and Rouot, B. (1997). Interaction of Yersinia enterocolitica with macrophages leads to macrophage cell death through apoptosis. Infect. Immun. 65, 4813-4821. 
Seshadri, R., Joseph, S. W., Chopra, A. K., Sha, J., Shaw, J., Graf, J., et al. (2006). Genome sequence of Aeromonas hydrophila ATCC 7966T: jack of all trades. J. Bacteriol. 188, 8272-8282. doi: 10.1128/JB.00621-06

Sha, J., Pillai, L., Fadl, A. A., Galindo, C. L., Erova, T. E., and Chopra, A. K. (2005). The type III secretion system and cytotoxic enterotoxin alter the virulence of Aeromonas hydrophila. Infect. Immun. 73, 6446-6457. doi: 10.1128/IAI.73.10.6446-6457.2005

Sha, J., Rosenzweig, J. A., Kozlova, E. V., Wang, S., Erova, T. E., Kirtley, M. L., et al. (2013). Evaluation of the roles played by Hcp and VgrG type 6 secretion system effectors in Aeromonas hydrophila SSU pathogenesis. Microbiology 159, 1120-1135. doi: 10.1099/mic.0.063495-0

Sha, J., Wang, S. F., Suarez, G., Sierra, J. C., Fadl, A. A., Erova, T. E., et al. (2007). Further characterization of a type III secretion system (T3SS) and of a new effector protein from a clinical isolate of Aeromonas hydrophila-part I. Microb. Pathog. 43, 127-146. doi: 10.1016/j.micpath.2007.05.002

Shrestha, N., Balnan, W., Wiley, D. J., Barber, G., Fields, K. A., and Schesser, K. (2012). Eukaryotic initiation factor 2(elF2) signaling regulates proinflammatory cytokine expression and bacterial invasion. J. Biol. Chem. 287, 28738-28744. doi: 10.1074/jbc.M112.375915

Sierra, J. C., Suarez, G., Sha, J., Baze, W. B., Foltz, S. M., and Chopra, A. K. (2010) Unraveling the mechanism of action of a new type III secretion system effector AexU from Aeromonas hydrophila. Microb. Pathog. 49, 122-134. doi: 10.1016/j.micpath.2010.05.011

Sierra, J. C., Suarez, G., Sha, J., Foltz, S. M., Popov, V. L., Galindo, C. L., et al. (2007). Biological characterization of a new type III secretion system effector from a clinical isolate of Aeromonas hydrophila-part II. Microb. Pathog. 43, 147-160. doi: 10.1016/j.micpath.2007.05.003

Silver, A. C., and Graf, J. (2009) Prevalence of genes encoding the type three secretion system and the effectors AexT and AexU in the Aeromonas veronii group. DNA Cell Biol. 28, 383-388. doi: 10.1089/dna.2009.0867

Strasser, A., O’Connor, L., and Dixit, V. M. (2000). Apoptosis signaling. Annu. Rev. Biochem. 69, 217-245. doi :10.1146/annurev.biochem.69.1.217

Su, B. H., Chiu, H. Y., Soga, T., Lin, K. J., and Hsu, C. T. (2007). Ulinastatin alone does not reduce caspase 3-mediated apoptosis in protease-positive Aeromonas hydrophilia-induced sepsis. J. Formos Med. Assoc. 106, 97-104. doi: 10.1016/S0929-6646(09)60224-2

Suarez, G., Sierra, J. C., Kirtley, M. L., and Chopra, A. K. (2010). Role of Hcp, a type 6 secretion system effector, of Aeromonas hydrophila in modulating activation of host immune cells. Microbiology 156, 3678-3688. doi: 10.1099/mic.0. 041277-0

Suarez, G., Sierra, J. C., Sha, J., Wang, S., Erova, T. E., Fadl, A. A., et al. (2008). Molecular characterization of a functional type VI secretion system from a clinical isolate of Aeromonas hydrophila. Microb. Pathog. 44, 344-361. doi: 10.1016/j.micpath.2007.10.005

Sundin, C., Hallberg, B., and Forsberg, A. (2004). ADP-ribosylation by exoenzyme $\mathrm{T}$ of Pseudomonas aeruginosa induces an irreversible effect on the host cell cytoskeleton in vivo. FEMS Microbiol. Lett. 234, 87-91. doi: 10.1111/j.15746968.2004.tb09517.x

Ulett, G. C., and Adderson, E. E. (2006). Regulation of apoptosis by gram-positive bacteria: mechanistic diversity and consequences for immunity. Curr. Immunol. Rev. 2, 119-141. doi: 10.2174/157339506776843033
Viboud, G. I., and Bliska, J. B. (2005). Yersinia outer proteins: role in modulation of host cell signaling responses and pathogenesis. Annu. Rev. Microbiol. 59, 69-89. doi: 10.1146/annurev.micro.59.030804.121320

Vilches, S., Jimenez, N., Tomás, J. M., and Merino, S. (2009) Aeromonas hydrophila AH-3 type III secretion system expression and regulatory network. Appl. Environ. Microbiol. 75, 6382-6392. doi: 10.1128/AEM.00222-09

Wu, C. J., Wang, H. C., Chen, C. S., Shu, H. Y., Kao, A. W., Chen, P. L., et al. (2012). Genome sequence of a novel human pathogen, Aeromonas aquariorum. J. Bacteriol. 194, 4114-4115. doi: 10.1128/JB.00621-12

Yagita, Y., Kuse, N., Kuroki, K., Gatanaga, H., Carlson, J. M., Chikata, T., et al. (2013) Distinct HIV-1 escape patterns selected by cytotoxic T cells with identical epitope specificity. J. Virol. 87, 2253-2263. doi: 10.1128/JVI.02572-12

Yu, H. B., Rao, P. S., Lee, H. C., Vilches, S., Merino, S., Tomas, J. M., et al. (2004). A type III secretion system is required for Aeromonas hydrophila AH1 pathogenesis. Infect. Immun. 72, 1248-1256. doi: 10.1128/IAI.72.3.12481256.2004

Zauberman, A., Cohen, S., Mamroud, E., Flashner, Y., Tidhar, A., Ber, R., et al. (2006). Interaction of Yersinia pestis with macrophages: limitations in YopJ-dependent apoptosis. Infect. Immun. 74, 3239-3250. doi: 10.1128/IAI.00 097-06

Zhang, W., Wang, Y., Song, Y., Wang, T., Xu, S., Peng, Z., et al. (2013). A type VI secretion system regulated by OmpR in Yersinia pseudotuberculosis functions to maintain intracellular pH homeostasis. Environ. Microbiol. 15, 557-569. doi: $10.1111 / 1462-2920.12005$

Zhang, W., Xu, S., Li, J., Shen, X., Wang, Y., and Yuan, Z. (2011) Modulation of a thermoregulated type VI secretion system by AHL-dependent quorum sensing in Yersinia pseudotuberculosis. Arch. Microbiol. 193, 351-363. doi: 10.1007/s00203-011-0680-2

Zheng, Y., Lilo, S., Mena, P., and Bliska, J. B. (2012). YopJ-induced caspase-1 activation in Yersinia-infected macrophages: independent of apoptosis, linked to necrosis, dispensable for innate host defense. PLoS ONE 7:e36019. doi: 10.1371/journal.pone.0036019

Conflict of Interest Statement: The authors declare that the research was conducted in the absence of any commercial or financial relationships that could be construed as a potential conflict of interest.

Received: 12 August 2013; accepted: 14 October 2013; published online: 30 October 2013.

Citation: Rosenzweig JA and Chopra AK (2013) Modulation of host immune defenses by Aeromonas and Yersinia species: convergence on toxins secreted by various secretion systems. Front. Cell. Infect. Microbiol. 3:70. doi: 10.3389/fcimb.2013.00070

This article was submitted to the journal Frontiers in Cellular and Infection Microbiology.

Copyright (C) 2013 Rosenzweig and Chopra. This is an open-access article distributed under the terms of the Creative Commons Attribution License (CC BY). The use, distribution or reproduction in other forums is permitted, provided the original author(s) or licensor are credited and that the original publication in this journal is cited, in accordance with accepted academic practice. No use, distribution or reproduction is permitted which does not comply with these terms. 